Aritoshi Iida - Susumu Saito - Akihiro Sekine

Satoko Harigae · Saori Osawa • Chihiro Mishima

Kimie Kondo • Yuri Kitamura • Yusuke Nakamura

\title{
Catalog of 46 single-nucleotide polymorphisms (SNPs) in the microsomal glutathione S-transferase 1 (MGST1) gene
}

\begin{abstract}
A major goal in our laboratory is to understand the role of common genetic variations among individual patients as regards susceptibility to common diseases and differences in therapeutic efficacy and/or side effects of drugs. As an addition to the high-density SNP (single-nucleotide polymorphism) maps of 12 glutathione S-transferase and related genes reported earlier, we provide here an SNP map of the microsomal glutathione S-transferase 1 (MGST1) gene. Among 48 healthy Japanese volunteers examined, we identified a total of 46 SNPs at this locus, 36 of which had not been reported before: 4 in the promoter region, 34 in introns, 3 in the $3^{\prime}$ untranslated region, and 5 in the $3^{\prime}$ flanking region. No SNP was found in 5' untranslated or coding regions. The ratio of transition to transversion was approximately 1.2:1. Among the 13 insertion-deletion polymorphisms was a 2-bp deletion in the coding region of $M G S T 1$ in DNA from one of the volunteers, which resulted in a frame-shift mutation. Since the gene product encoded by this mutant allele would lack the C-terminal half including the MAPEG (membrane-associated proteins in eicosanoid and glutathione metabolism) domain, MGST1 activity is likely to be reduced in the carrier's cells. The SNP map presented here adds to the archive of tools for studying complex genetic diseases, population migration patterns, and a variety of pharmacogenetic possibilities.
\end{abstract}

Key words Single-nucleotide polymorphisms (SNPs) • Highly dense SNP map - Microsomal glutathione Stransferase 1 (MGST1) · MAPEG family · Insertiondeletion polymorphisms $\cdot$ Japanese population

A. Iida $\cdot$ S. Saito $\cdot$ A. Sekine $\cdot$ S. Harigae $\cdot$ S. Osawa $\cdot$ C. Mishima K. Kondo $\cdot$ Y. Kitamura Y. Nakamura Laboratory for Genotyping, RIKEN SNP Research Center, Tokyo, Japan

Y. Nakamura $(\bowtie)$

Laboratory of Molecular Medicine, Human Genome Center, Institute of Medical Science, University of Tokyo, 4-6-1

Shirokanedai, Minato-ku, Tokyo 108-8639, Japan

Tel. +81-3-5449-5372; Fax +81-3-5449-5433

e-mail: yusuke@ims.u-tokyo.ac.jp

\section{Introduction}

Glutathione S-transferases (GSTs, EC 2.5.1.18) constitute a group of phase II detoxification enzymes present in eukaryotic cells and prokaryotic organisms; they play significant roles in defense against carcinogenic, toxic, and pharmacologically active electrophilic compounds (Ketterer and Christodoulides 1994; Primiano et al. 1997). Microsomal glutathione S-transferase 1 (MGST1) is a homotrimeric, membrane-bound enzyme that catalyzes conjugation of electrophilic compounds with glutathione and reduction of lipid hydroperoxides (Andersson et al. 1994; Mosialou et al. 1993, 1995). Peroxidase activity may be of importance for protection against lipid peroxidation under conditions of oxidative stress. Although soluble and membrane-bound GSTs are not related with respect to amino acid sequences and immunological properties, they do display extensive functional similarities (Morgenstern et al. 1982; DeJong et al. 1988; Andersson et al. 1994; Mosialou et al. 1995). A number of biochemical approaches have been used to study the properties of MGST1, including enzymic activity, sub-cellular distribution, substrate specificity, and proteins structure (Andersson et al. 1994; Weinander et al. 1997; Bannenberg et al. 1999; Schmidt-Krey et al. 2000; Morgenstern et al. 2001). MGST1 is considered a member of the MAPEG (membrane-associated proteins in eicosanoid and glutathione metabolism) superfamily of structurally and phylogenetically related enzymes, including MGST2, MGST3, MGST1L1, 5-lipoxygenase activating protein, and leukotriene C4 synthase. Enzymes in this superfamily are involved in detoxification, protection from oxidative stress, and synthesis of prostaglandin $\mathrm{E}$ and cysteinyl leukotrienes (for reviews, see Jakobsson et al. 1999, 2000).

MGST1, which is abundant in liver microsomes as well as in the outer mitochondial membrane, has been purified from rat, mouse, and human tissues (Morgenstern et al. 1982, 1984; Andersson et al. 1988; McLellan et al. 1989). The cDNAs of human and rat MGST1 contain open reading frames encoding 155 amino acid polypeptides, and the 
two proteins are $85 \%$ identical in amino acid sequence (DeJong et al. 1988). The human MGST1 gene spans approximately $18 \mathrm{~kb}$ of genomic DNA; of its seven exons, three comprise the coding element and four are alternatively spliced first exons (Kelner et al. 1996; Lee and DeJong 1999). Kelner et al. (2000) reported in detail the structural organization of the $5^{\prime}$ untranslated region of human MGST1, including two functional first exons (exon $1 \mathrm{~b}$, 1d) and the promoter region, and mapped MGST1 to chromosome 12p13.1-p13.2. Simultaneously, they discovered that the promoter region of MGST1 upstream of the dominant first exon (exon 1b) is involved in the response to oxidative stress as a detoxification mechanism. Using a microarray technique, Chaib et al. (2001) recently established that expression of MGST1 in human prostate tumors was twice that of normal tissues.

We have been focusing on variations in genomic regions that contain genes encoding enzymes involved in metabolism of drugs, and have described more than 1200 SNPs and other variations (Iida et al. 2001a,b,c; Saito et al. 2001a,b; Sekine et al. 2001). Regarding GST and related genes, we have already constructed high-density SNP maps of 12 genomic segments that included GSTM1, GSTM2, GSTM3, GSTM4, GSTZ1, GSTPi, GSTT1, MGST1L1, MGST2, MGST3, GSTA1, and GSTA4 (lida et al. 2001b), providing a total of 127 SNPs for these loci. In the study reported here, we screened a Japanese population sample for SNPs at the $M G S T 1$ locus, as a $13^{\text {th }}$ gene member of the GST family, by means of direct sequencing combined with a polymerase chain reaction (PCR) method for genomic DNA, and characterized 46 SNPs and 13 insertion-deletion polymorphisms.

\section{Subjects and methods}

Blood samples were obtained with written informed consent from 48 healthy Japanese volunteers for this study, which was approved by the ethical committee of the RIKEN SNP Research Center. On the basis of the MGST1 DNA sequence (accession number AC007528.5) from the GenBank database and published reports (DeJong et al. 1988; Kelner et al. 1996, 2000; Lee and DeJong 1999), we designed primers to amplify the $M G S T 1$ gene in its entirety, as well as $2 \mathrm{~kb}$ upstream from the first exon and downstream from the last exon. However, we excluded most of the regions corresponding to repetitive sequences predicted by the RepeatMasker program from the screening protocol. DNA extraction, PCR experiments, and DNA sequencing were performed according to methods described previously (Ohnishi et al. 2000). Each PCR was carried out using $20 \mathrm{ng}$ of DNA pooled from three individuals. All SNPs detected by the PolyPhred Computer Program (Nickerson et al. 1997) were confirmed by sequencing both strands of each PCR product.

\section{Results and discussion}

The highly dense SNP map of the 21-kb genomic region presented here contains the entire human MGST1 gene. The RepeatMasker program predicted the presence of nine copies of Alu sequence, six copies of mammalian interspersed repetitive element (MIR) sequence, three copies of L1 sequence, one L2 sequence, and one mammalianwide apparent long terminal repeat transposon (MaLR) sequence, comprising in total approximately $24 \%$ of this $21 \mathrm{~kb}$ of genomic DNA. Nineteen partially overlapping PCR fragments were selected and sequenced using a total of 76 sequence primers. The exon organization of the MGST1 gene and locations of identified SNPs are illustrated schematically in Figure 1. We documented 46 SNPs in the MGST1 locus: 4 in the promoter region, 34 in introns, 3 in $3^{\prime}$ untranslated regions, and 5 in the $3^{\prime}$ flanking region (Table 1, also see Figure 1). No SNP was detected in $5^{\prime}$ untranslated or coding regions. Since we had found no SNPs in the 5' untranslated or coding regions of other members of the MAPEG family examined in a previous study [MGST1L1, MGST2, and MGST3 (Iida et al. 2001b)], we suspect that there might be strong selective pressure to conserve sequences in these regions. As regards the four SNPs upstream of the dominant first exon $1 \mathrm{~b}$ (Kelner et al. 2000), three were adjacent to transcription-factor binding sites: i-MGST-2 and i-MGST-3 were located $7 \mathrm{bp}$ upstream of the binding site of EpRE/EBP40 and 8bp downstream of the HNF3 binding site, respectively; both of those sites appear to have some association with hepatocyte-specific gene expression (Kelner et al. 2000) and i-MGST-4 was located 2 bp upstream of an Sp1 binding site. These three SNPs might affect the quantity of gene product in response to oxidative stress.

After comparing our data with the National Center for Biotechnology Information (NCBI) dbSNP database, we considered $36(78.2 \%)$ of the SNPs listed in Table 1 to be novel. Their overall genomic distribution was $1 / 364$ bp in the $16.7 \mathrm{~kb}$ of DNA we sequenced. The frequencies of nucleotide substitutions were counted as $34.8 \%$ for $\mathrm{C} / \mathrm{T}$, $19.6 \%$ for $\mathrm{A} / \mathrm{G}, 19.6 \%$ for $\mathrm{G} / \mathrm{T}, 15.2 \%$ for $\mathrm{C} / \mathrm{G}, 6.5 \%$ for $\mathrm{A} / \mathrm{T}$, and $4.3 \%$ for $\mathrm{A} / \mathrm{C}$. The ratio of transitions to transversions was approximately 1.2:1. This ratio in other MAPEG gene loci (MGST1L1, MGST2, and MGST3) had been established as $1.5: 1,3: 1$, and $0.9: 1$ respectively.

We also identified 13 novel insertion-deletion polymorphisms within introns 1C, 2, and 3; exon 3; and the $3^{\prime}$ flanking region of the MGST1 gene (Table 2). One of these was a 2 bp deletion in exon 3 that would cause a frame-shift mutation; the altered allele would generate a gene product lacking the C-terminal half that contains the MAPEG domain. Hence this result suggests that MGST1 activity is likely to be reduced in the carrier's cells. However, since this mutation was found in a healthy volunteer, we have no information regarding its potential effect on the carrier's susceptibility to any disease or drug response.

Altogether we have collected a total of 173 SNPs among 13 GSTs and related genes in the Japanese population. As 
$0 \mathrm{~kb}$

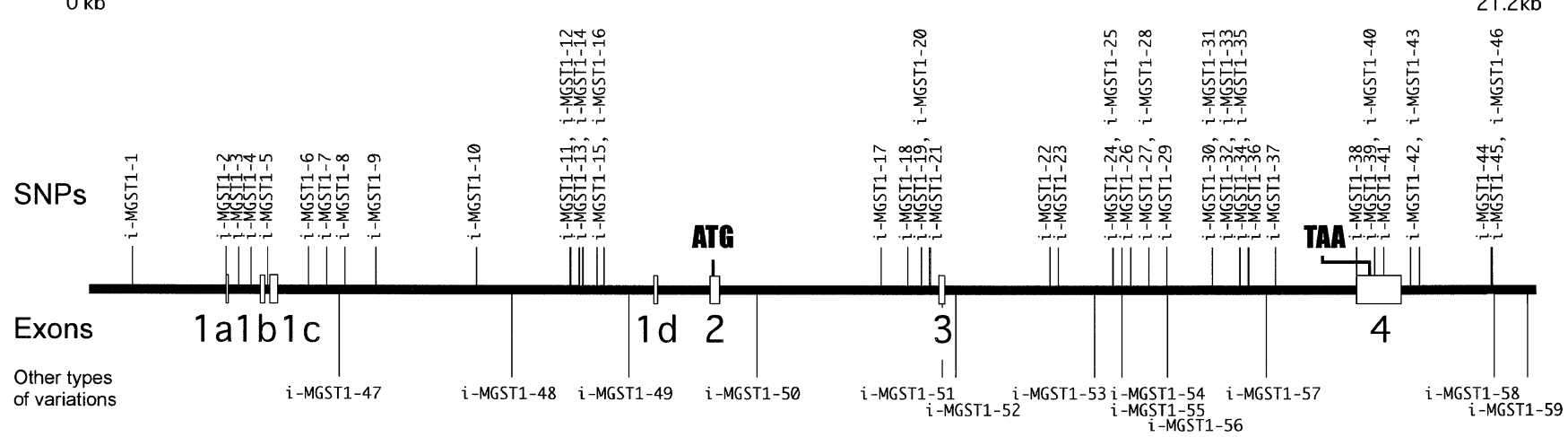

Fig. 1. $S N P$ map spanning the $21-\mathrm{kb}$ genomic region containing the MGST1 gene. Exons are represented by vertical boxes or a line. The 46 SNPs are identified above the gene (designations correspond to the identification (ID) numbers in the left-most column on Table 1); locations of the 13 insertion-deletion polymorphisms listed in Table 2 are indicated below the gene. Detailed information of variations isolated in this study is shown in Table 1 and Table 2 . The region upstream of the dominant transcription initiation site at exon $1 b$ is defined as the promoter region on the basis of a report described by Kelner et al (2000)

Table 1. Characterization of SNPs from the MGST1 gene locus

\begin{tabular}{|c|c|c|c|c|c|c|c|}
\hline ID & location & & & SNP (5' to $\left.3^{\prime}\right)$ & & repetitive seq. & dbSNP ID number \\
\hline i-MGST1-1 & promoter region & -1879 & ttaataaatgtttattcaat & $T / G$ & aaaccaactgctaatattct & & \\
\hline i-MGST1-2 & promoter region & -508 & tctggaccctgaacaggagg & $\mathrm{G} / \mathrm{C}$ & gacatcgtgacaaagcaaat & & \\
\hline i-MGST1-3 & promoter region & -314 & cctggagattttaactttct & $\mathrm{G} / \mathrm{A}$ & cgaagtttttaaaaacaact & & \\
\hline i-MGST1-4 & promoter region & -131 & atcagcaggcgatggttact & $\mathrm{G} / \mathrm{C}$ & tgggcgggtaaatcaggtga & & \\
\hline i-MGST1-5 & intron $1 \mathrm{~b}$ & 36 & ggagaaggggaccgcatgca & A/G & agggtggcaggcagggaggg & & \\
\hline i-MGST1-6 & intron1c & 456 & cccettgggacggttctcac & $\mathrm{C} / \mathrm{T}$ & tgtgccccacttecccagtc & & \\
\hline i-MGST1-7 & intron1c & 719 & gccegcaagcattgctgtat & A/G & gcacccaggcetccagtgag & & \\
\hline i-MGST1-8 & intron1c & 985 & cgagtaaaattttctaccg & $\mathrm{C} / \mathrm{G}$ & tttgttttagagtggtgtct & & \\
\hline i-MGST1-9 & intron1c & 1428 & gtaaagggaaagggcgttcc & T/A & caactgagaagtgaagattc & & \\
\hline i-MGST1-10 & intron1c & 2914 & ctcatcaggtgtgtgtcaga & $T / G$ & gcttggtgctggccagtctc & & \\
\hline i-MGST1-11 & intron1c & 4274 & attgtaatagattaacaaag & $\mathrm{G} / \mathrm{T}$ & tgatgaaagtagtgtacata & & \\
\hline i-MGST1-12 & intron $1 \mathrm{c}$ & 4276 & tgtaatagattaacaaaggt & $\mathrm{G} / \mathrm{T}$ & atgaaagtagtgtacataat & & \\
\hline i-MGST1-13 & intron1c & 4406 & gatggctatatgaccaataa & $\mathrm{A} / \mathrm{T}$ & gatacatataaatgtataga & & rs1913262 \\
\hline i-MGST1-14 & intron1c & 4464 & agaaagattgcagctgatag & $\mathrm{G} / \mathrm{A}$ & tgtcaggctaataaggacac & & rs1913263 \\
\hline i-MGST1-15 & intron1c & 4683 & aatggcagaggactggaaat & $\mathrm{G} / \mathrm{T}$ & tacattttaagetttaccet & & rs1913264 \\
\hline i-MGST1-16 & intron1c & 4767 & gccttcctcttcagcacatt & $\mathrm{C} / \mathrm{T}$ & ccaattatacttccaattcc & & \\
\hline i-MGST1-17 & intron2 & 2379 & ttctcaaatttcattataca & $\mathrm{G} / \mathrm{C}$ & tattcttcaacccaaagttt & & \\
\hline i-MGST1-18 & intron2 & 2767 & tttaactatagatgccttct & $T / G$ & ctcctcttgtgtttgattta & & \\
\hline i-MGST1-19 & intron2 & 2974 & tcactgcagcctcaacctct & $\mathrm{C} / \mathrm{T}$ & gggctcaggtgatcetccaa & + & \\
\hline i-MGST1-20 & intron2 & 3083 & aaaaatttgtagatatggg & T/G & actcectatgttgcccaggc & + & \\
\hline i-MGST1-21 & intron2 & 3106 & tccetatgttgeccaggetg & A/G & tcttgaattcttgggctcaa & + & \\
\hline i-MGST1-22 & intron3 & 1495 & gtcagacaatggcettcagc & $\mathrm{G} / \mathrm{A}$ & tcctctctttgcagaatatg & & \\
\hline i-MGST1-23 & intron3 & 1703 & ttctcttctaagaagaagtc & $\mathrm{T} / \mathrm{C}$ & gtgcagatacttagcacaaa & & \\
\hline i-MGST1-24 & intron3 & 2528 & ttttggagacacttttcaga & $\mathrm{G} / \mathrm{C}$ & agagcgtttccagcatcttc & & \\
\hline i-MGST1-25 & intron3 & 2557 & tccagcatcttcectttcca & $\mathrm{T} / \mathrm{C}$ & ttttaagttagacttttttt & & \\
\hline i-MGST1-26 & intron3 & 2731 & atacacatatggaacaatta & $\mathrm{A} / \mathrm{C}$ & ctaaaaacttaaggtaatat & & \\
\hline i-MGST1-27 & intron3 & 3032 & agagacatttagaatatatt & C/A & cctttaaggtagagaataa & & \\
\hline i-MGST1-28 & intron 3 & 3045 & atatattccetttaaaggta & $\mathrm{G} / \mathrm{C}$ & agaataaccettcactgaga & & \\
\hline i-MGST1-29 & intron 3 & 3289 & ggtttatagtgttccecccc & T/A & cccogcecccaaaagaccca & & \\
\hline i-MGST1-30 & intron 3 & 3885 & gaagctgccgetccaggaag & $\mathrm{G} / \mathrm{C}$ & agtctgtcgttggagaagag & & rs1006874 \\
\hline i-MGST1-31 & intron 3 & 3976 & ggaaagctggggaactgttt & $\mathrm{G} / \mathrm{T}$ & cctggaacagagtctcaaaa & & \\
\hline i-MGST1-32 & intron3 & 4288 & ccattctatttgtcaactgc & $\mathrm{G} / \mathrm{A}$ & taacacaggcgtagaagtgg & & \\
\hline i-MGST1-33 & intron 3 & 4298 & tgtcaactgcgtaacacagg & $\mathrm{C} / \mathrm{T}$ & gtagaagtggacattgtttt & & \\
\hline i-MGST1-34 & intron3 & 4378 & aaatgtctgtccttttggca & $\mathrm{T} / \mathrm{C}$ & gttgtgaaggagaacactaa & & rs1828682 \\
\hline i-MGST1-35 & intron 3 & 4429 & attggaggtgacgatatctc & $\mathrm{T} / \mathrm{C}$ & gtgatgctgggggagaaatc & & \\
\hline i-MGST1-36 & intron 3 & 4519 & tttaatagaaaatggtattc & $\mathrm{C} / \mathrm{T}$ & tgtcttttctttcccatctc & & \\
\hline i-MGST1-37 & intron3 & 4817 & attgctatagaagagagtaa & $\mathrm{C} / \mathrm{T}$ & gtaaagcagaaatagttttc & & \\
\hline i-MGST1-38 & intron3 & 6077 & tttgaaattagtgtctttaa & $\mathrm{T} / \mathrm{C}$ & agttatctttttccacagag & & \\
\hline i-MGST1-39 & $3^{\prime}$ untranslated region & 487 & aaagaaatcatacaactca & G/A & catccagttggctttttaag & & rs11875 \\
\hline i-MGST1-40 & $3^{\prime}$ untranslated region & 525 & aagaattctgtacttccaat & $T / G$ & tataatgaatactttcttag & & rs1042669 \\
\hline i-MGST1-41 & $3^{\prime}$ untranslated region & 603 & gggtaaacccattttgaata & $\mathrm{T} / \mathrm{C}$ & tagcattgccaatatcctgt & & \\
\hline i-MGST1-42 & 3' flanking region & 147 & tatttgctttccttctctct & $\mathrm{C} / \mathrm{T}$ & tgttttcttttectctgaaa & + & \\
\hline i-MGST1-43 & $3^{\prime}$ flanking region & 237 & cagcacgtttttcctatgaa & $\mathrm{C} / \mathrm{T}$ & aagacattctccaaataact & + & \\
\hline i-MGST1-44 & 3' flanking region & 1318 & tggctctgtgtgcatgaaca & $\mathrm{T} / \mathrm{C}$ & gcacgcgtgcacgcgcacac & & rs 1024834 \\
\hline i-MGST1-45 & $3^{\prime}$ flanking region & 1322 & tctgtgtgcatgaacatgca & $\mathrm{C} / \mathrm{T}$ & gcgtgcacgcgcacacacac & & rs1024835 \\
\hline i-MGST1-46 & 3' flanking region & 1331 & atgaacatgcacgcgtgcac & G/A & cgcacacacacacacacaca & + & rs 1024837 \\
\hline
\end{tabular}

Nucleotide numbering is according to mutation nomenclature (Dunnen and Antonarakis, 2000)

MGST1, microsomal glutathione S-transferase 1 
Table 2. Characterization of insertion-deletion polymorphisms from MGST1 gene locus

\begin{tabular}{|c|c|c|c|c|c|c|}
\hline ID & location & & & Variation (5' to $\left.3^{\prime}\right)$ & & repetitive seq \\
\hline i-MGST1-47 & intron1C & 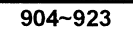 & tgcgattatctttggtaatt & $(A)_{16-19}$ & ggcaaatcagtccaaatttg & \\
\hline i-MGST1-48 & intron1C & $3433 \sim 3434$ & cccttcaatactagaacaa & AAlins & gcagacacattaaatgttac & \\
\hline i-MGST1-49 & intron1C & 5146 & actatttcaatttttttttt & T/del & ggagggggagacagagtctc & + \\
\hline i-MGST1-50 & intron2 & $552 \sim 563$ & cccagcattataagaatgac & $(T)_{10-12}$ & aagtgcagatgtggggaggg & \\
\hline i-MGST1-51 & exon3 & 172 173 & tagcatttggcaaaggagaa & AA/del & tgccaagaagtatcttcgaa & \\
\hline i-MGST1-52 & intron3 & 152 158 & agaaaactggatgtctgaaa & TTGACA/delGTCCAATAT/ins & cactgcacttgtatgtgttg & \\
\hline i-MGST1-53 & intron3 & $2198 \sim 2200$ & ggattttagattcctcceta & CTA/del & ttctttccgaccttccacce & \\
\hline i-MGST1-54 & intron3 & 2567 2568 & ccetttccatttttaagtta & Alins & gactttettttttcacctct & \\
\hline i-MGST1-55 & intron3 & 2571 2580 & tttccatttttaagttagac & $(T)_{9.11}$ & cacctctctcgttacttcag & \\
\hline i-MGST1-56 & intron3 & $3288 \sim 3289$ & ggtttatagtgttceccecc & C/ins & tccccgeccccaaaagaccc & \\
\hline i-MGST1-57 & intron3 & $4682 \sim 4683$ & tcctcttcatgtctctatgt & GAGATGTTGTGGCTCACAT/ins & agtcatcctctttgtgagac & \\
\hline i-MGST1-58 & 3' flanking region & 1359 1360 & acacacacacacacacacac & $\mathrm{CC} / \mathrm{del}$ & tgctctggagttgggcaact & \\
\hline i-MGST1-59 & $3^{\prime}$ flanking region & 1889 1891 & ttagaatagtttctaactat & ACT/del & tttactcccaagagaagctt & \\
\hline
\end{tabular}

Nucleotide numbering is according to mutation nomenclature (Dunnen and Antonarakis 2000)

ins, insertion polymorphism; del, deletion polymorphism

an adjunct to this work, we have been able to establish a high-throughput system for genotyping up to 100 million SNPs per year, using a multiplex PCR method with the Invader assay (Ohnishi et al. 2001). In the near future, this powerful system will provide data that should assist in efforts to reach the goal of personalized medicine, and should be useful also for identifying genes involved in drug efficacy and/or side effects.

All data collected so far concerning SNPs in genes encoding drug-metabolizing enzymes and the sequences of primers used for PCR and PCR conditions are available on our website (http://snp.ims.u-tokyo.ac.jp/).

\section{References}

Andersson C, Soderstrom M, Mannervik B (1988) Activation and inhibition of microsomal glutathione transferase from mouse liver. Biochem J 249:819-823

Andersson C, Mosialou E, Weinander R, Morgenstern R (1994) Enzymology of microsomal glutathione S-transferase. In: Anders MW, Dekant W (eds) Advances in pharmacology, conjugation-dependent carcinogenicity and toxicity of foreign compounds, vol. 27. Academic Press, San Diego, pp 19-35

Bannenberg G, Dahlen SE, Luijerink M, Lundqvist G, Morgenstern R (1999) Leukotriene C4 is a tight-binding inhibitor of microsomal glutathione transferase- 1 . Effects of leukotriene pathway modifiers. J Biol Chem 274:1994-1999

Chaib H, Cockrell EK, Rubin MA, Macoska JA (2001) Profiling and verification of gene expression patterns in normal and malignant human prostate tissues by cDNA microarray analysis. Neoplasia 3:43-52

DeJong JL, Morgenstern R, Jornvall H, DePierre JW, Tu CP (1988) Gene expression of rat and human microsomal glutathione Stransferases. J Biol Chem 263:8430-8436

Dunnen JT, Antonarakis SE (2000) Mutation nomenclature extensions and suggestions to describe complex mutations: a discussion. Hum Mutat 15:7-12

Iida A, Sekine A, Saito A, Kitamura Y, Kitamoto T, Osawa S, Mishima C, Nakamura Y (2001a) Catalog of 320 single nucleotide polymorphisms (SNPs) in 20 quinone oxidoreductase and sulfotransferase genes. J Hum Genet 46:225-240

Iida A, Saito S, Sekine A, Kitamoto T, Kitamura Y, Mishima C, Osawa S, Kondo K, Harigae S, Nakamura Y (2001b) Catalog of 434 singlenucleotide polymophisms (SNPs) in genes of the alcohol dehydrogenase, glutathione S-transferase genes, and nicotineamide adenine dinucleotide, reduced (NADH) ubiquinone oxidoreductase families. J Hum Genet 46:385-407
Iida A, Satio S, Sekine A, Kitamura Y, Kondo K, Mishima C, Osawa S, Harigae S, Nakamura Y (2001c) High-density single-nucleotide polymorphism (SNP) map spanning the 150 -kb region corresponding to the human ATP-binding cassette transporter $\mathrm{A} 1$ ( $A B C A 1)$ gene. J Hum Genet 46:522-528

Jakobsson PJ, Morgenstern R, Mancini J, Ford-Hutchinson A, Persson B (1999) Common structural features of MAPEG - a widespread superfamily of membrane associated proteins with highly divergent functions in eicosanoid and glutathione metabolism. Protein Sci 8:689-692

Jakobsson PJ, Morgenstern R, Mancini J, Ford-Hutchinson A, Persson B (2000) Membrane-associated proteins in eicosanoid and glutathione metabolism (MAPEG). A widespread protein superfamily. Am J Respir Crit Care Med 161:S20-S24

Kelner MJ, Stokely MN, Stovall NE, Montoya MA (1996) Structural organization of the human microsomal glutathione S-transferase gene (GST12). Genomics 36:100-103

Kelner MJ, Bagnell RD, Montoya MA, Estes LA, Forsberg L, Morgenstern R (2000) Structural organization of the microsomal glutathione S-transferase gene (MGST1) on chromosome 12p13.113.2. Identification of the correct promoter region and demonstration of transcriptional regulation in response to oxidative stress. $\mathrm{J}$ Biol Chem 275:13000-13006

Ketterer B and Christodoulides L (1994) Enzymology of cytosolic glutathione S-transferases. In: Anders MW, Dekant W (eds) Advances in pharmacology, conjugation-dependent carcinogenecity and toxicity of foreign compounds, vol. 27. Academic Press, San Diego, pp 37-69

Lee SH, DeJong J (1999) Microsomal GST-I: genomic organization, expression, and alternative splicing of the human gene. Biochim Biophys Acta 1446:389-396

McLellan LI, Wolf CR, Hayes JD (1989) Human microsomal glutathione S-transferase. Its involvement in the conjugation of hexachlorobuta-1,3-diene with glutathione. Biochem J 258:8793

Morgenstern R, Guthenberg C, Depierre (1982) Microsomal glutathione S-transferase. Purification, initial characterization and demonstration that it is not identical to the cytosolic glutathione S-transferases A, B and C. Eur J Biochem 128:243-248

Morgenstern R, Lundqvist G, Andersson G, Balk L, DePierre JW (1984) The distribution of microsomal glutathione transferase among different organelles, different organs, and different organisms. Biochem Pharmacol 33:3609-3614

Morgenstern R, Svensson R, Bernat BA, Armstrong RN (2001) Kinetic analysis of the slow ionization of glutathione by microsomal glutathione transferase MGST1. Biochemistry 40:3378-3384

Mosialou E, Ekstrom G, Adang AE, Morgenstern R (1993) Evidence that rat liver microsomal glutathione transferase is responsible for glutathione-dependent protection against lipid peroxidation. Biochem Pharmacol 45:1645-1651

Mosialou E, Piemonte F, Andersson C, Vos RM, van Bladeren PJ, Morgenstern R (1995) Microsomal glutathione transferase: lipidderived substrates and lipid dependence. Arch Biochem Biophys 320:210-216 
Nickerson DA, Tobe VO, Taylor SL (1997) PolyPhred: automating the detection and genotyping of single nucleotide substitutions using fluorescence-based resequencing. Nucleic Acids Res 25:2745-2751

Ohnishi Y, Tanaka T, Yamada R, Suematsu K, Minami M, Fujii K, Hoki N, Kodama K, Nagata S, Hayashi T, Kinoshita N, Sato H, Sato H, Kuzuya T, Takeda H, Hori M, Nakamura Y (2000) Identification of 187 single nucleotide polymorphisms (SNPs) among 41 candidate genes for ischemic heart disease in the Japanese population. Hum Genet 106:288-292

Ohnishi Y, Tanaka T, Ozaki K, Yamada R, Suzuki H, Nakamura Y (2001) A high-throughput SNP typing system for genome-wide association studies. J Hum Genet 46:471-477

Primiano T, Sutter TR, Kensler TW (1997) Antioxidant-inducible genes. In: Sies H (ed) Advance in pharmacology, antioxidants in disease mechanisms and therapy, vol. 38. Academic Press, San Diego, pp 293-328

Saito S, Iida A, Sekine A, Eguchi C, Miura Y, Nakamura Y (2001a) Seventy genetic variations in human microsomal and soluble epoxide hydrolase (EPHX1 and EPHX2) genes in the Japanese population. J Hum Genet 46:325-329
Saito S, Iida A, Sekine A, Miura Y, Sakamoto T, Ogawa C, Kawauchi S, Higuchi S, Nakamura Y (2001b) Identification of 197 genetic variations in six human methyltransferase genes in the Japanese population. J Hum Genet 46:529-537

Sekine A, Saito S, Iida A, Mitsunobu Y, Higuchi S, Harigae S, Nakamura Y (2001) Identification of single nucleotide polymorphisms (SNPs) of human N-acetyltransferase genes NAT1, NAT2, AANAT, ARD1 and L1CAM in the Japanese population. J Hum Genet 46:314-319

Schmidt-Krey I, Mitsuoka K, Hirai T, Murata K, Cheng Y, Fujiyoshi Y, Morgenstern R, Hebert H (2000) The three-dimensional map of microsomal glutathione transferase 1 at $6 \AA$ resolution. EMBO J 19:6311-6316

Weinander R, Ekstrom L, Andersson C, Raza H, Bergman T, Morgenstern R (1997) Structural and functional aspects of rat microsomal glutathione transferase. The roles of cysteine 49, arginine 107 , lysine 67 , histidine, and tyrosine residues. J Biol Chem 272:8871-8877 